\title{
THE PATHOLOGY OF THE DEGENERATE MENISCUS LESION
}

\author{
Jonathan Noble, Edinburgh, and David L. Hamblen, Glasgow, Scotland
}

\author{
From the Princess Margaret Rose Orthopaedic Hospital, Edinburgh, and the University of Glasgow.
}

\begin{abstract}
The incidence of horizontal cleavage lesions of the menisci was studied in 100 random necropsy examinations. Sixty per cent of subjects had at least one such tear, the incidence being 29 per cent out of the $\mathbf{4 0 0}$ menisci. Eighty-five per cent of the subjects showed changes of osteoarthritis in the patello-femoral or tibio-femoral joint compartments. The coincidence of horizontal cleavage lesion and osteoarthritis was frequent. Horizontal cleavage lesions were commoner in medial or larger menisci and in males. Eighteen per cent of the menisci were calcified and this was twice as common in those menisci with a degenerate tear. Because the horizontal cleavage lesion was so common in the older knee, it must usually remain unrecognised clinically with other factors causing symptoms of night pain and tenderness.
\end{abstract}

The term horizontal cleavage lesion was first used by Smillie (1962) to describe a degenerative tear in the horizontal plane of the meniscus, usually in its posterior half. He distinguished such tears from those that were acute, traumatic and longitudinal in which the tear was vertical or oblique. In his department horizontal tears accounted for at least half the menisci removed surgically (Smillie 1967). Apart from a necropsy report (Chand 1972) no other workers have described the horizontal cleavage lesion as a primary pathological diagnosis, although degenerative lesions have been recognised for some years (Smith and Blair 1954; Sideman and Siegel 1962; Simmonds 1964; Zippel 1964; Pfeil 1966; Tarjany and Radochay 1966; Eichenholtz, Jacobs and Patterson 1968; Lidge 1970).

It seemed that degenerative tears might be more common in the elderly, and to investigate this the incidence of the horizontal cleavage lesion has been studied in necropsy cases and related to other intraarticular pathology.

\section{METHOD}

One hundred random necropsy cases of known height, weight and age were studied in a general hospital (Royal Infirmary of Edinburgh). Both knees were opened through a wide transverse incision and both pairs of menisci were removed and preserved in formol-saline. The extent and pattern of osteoarthritis of the patellofemoral and tibio-femoral articulations were noted and a semi-quantitative grading made: 0 , no osteoarthritis; 1 , peripheral osteophytes or articular surface fibrillation with no frank erosions; 2 , presence of cartilage erosions; 3 , deep ulceration with eburnation or gross osteophytes. The state of the cruciate ligaments and the presence of

loose bodies were noted: after removal the menisci were radiographed for calcification at a standard magnification by a soft-tissue technique (Scott, Willemin and Betsch 1967).

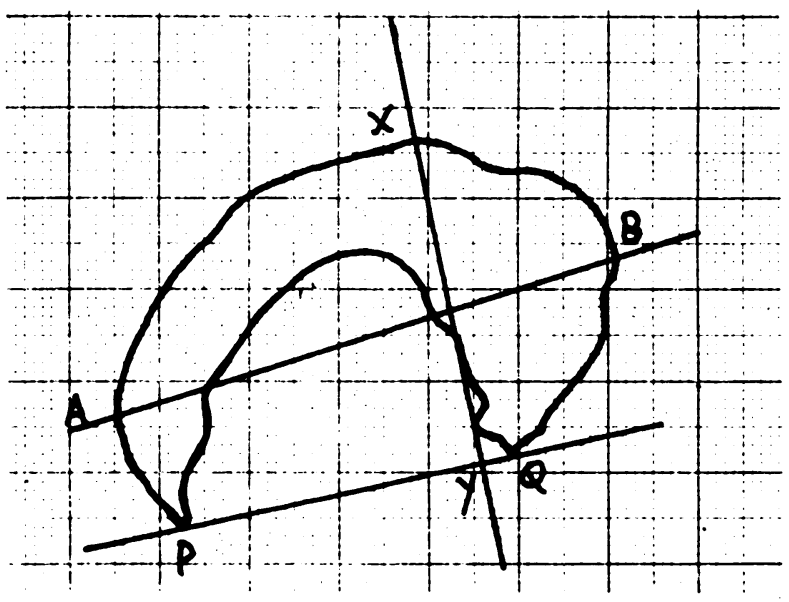

Fig. 1

Relating measured surface area to length breadth product. Measured surface area . $. \quad . \quad .9 .7$ centimetres

Maximum length (AB)

Maximum breadth (XY)

$\therefore$ length breadth product

From the graph in Figure 2 the length breadth product of 20.3 centimetres is proportional to surface area of 9.9 centimetres:.

The surface area of the meniscus was determined from the radiographs by copying the outlines on to squared graph paper so that the area of squares could be counted. This was laborious and inaccurate when the central border of the meniscus was frayed by degeneration. Therefore other measurements were made from the radiographs to compare the surface areas. Figure 1

Jonathan Noble, F.R.C.S.Ed., Chalmers House, 23 Chalmers Street, Edinburgh EH3 9EW, Scotland.

David L. Hamblen, F.R.C.S., Professor of Orthopaedic Surgery, University of Glasgow, Scotland. 
shows a line $A B$ drawn to represent the greatest length of the meniscus and a second line PQ goes between the anterior and posterior horns; a perpendicular line $\mathrm{XY}$ is dropped from it to the point on the periphery of the

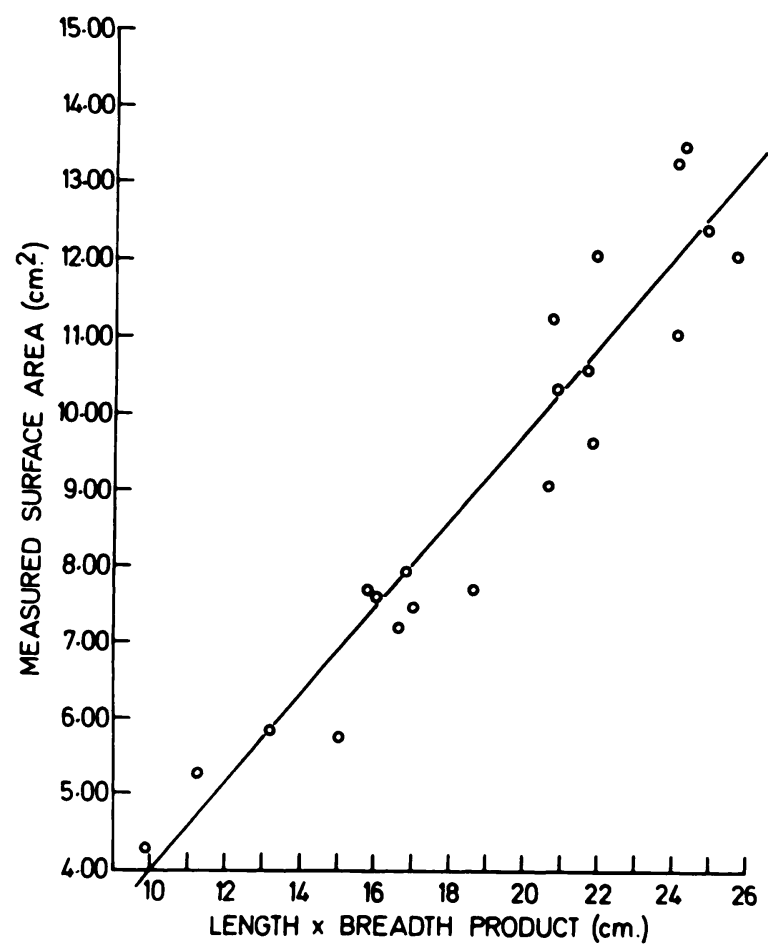

FIG. 2

Graph relating surface area to length $\because$ breadth product for twenty-one normal medial menisci.

meniscus farthest from $P Q$ and is the greatest breadth of the meniscus. When the product of $A B$ times $X Y$ was plotted graphically against the measured surface area for eighteen normal lateral menisci and twenty-one normal

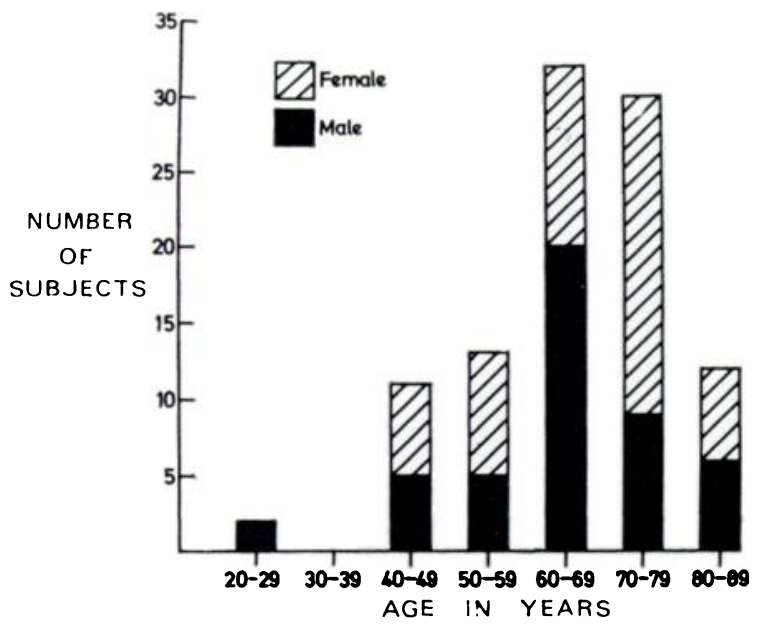

FIG. 3

The age distribution of the necropsy subjects.

medial menisci (Fig. 2) a good correlation was obtained. The greatest length and breadth was measured for the rest of the menisci in the same way as the surface area calculated separately for the medial and lateral menisci.
All menisci were studied in serial macroscopic sections and representative sections were studied histologically using Van Gieson, haematoxylin and eosin, and Von Kossa stains, and under conventional and polarised light.

TABLE I

INCIDENCF OF MeNisCus Lesions

\begin{tabular}{lccc}
\hline & Cadavers & Menisci \\
\hline Number . & $\frac{100}{400}$ \\
\hline Nature of lesion & & Per cent & Per cent \\
\hline Horizontal cleavage . & 60 & 29 \\
Parrot beak tear &. & 27 & 7.5 \\
Longitudinal tear &. & 12 & 3 \\
Cystic degeneration . &. & 20 & $6 \cdot 75$ \\
Discoid meniscus &. & 5 & 2 \\
Calcification or ossification & 34 & 18 \\
\hline Total with lesions &. & 73 & 34 \\
\hline Total with no lesions &. & 27 & 66 \\
\hline
\end{tabular}

\section{RESULTS}

Age and sex-The age distribution for this series is shown in Figure 3. The average age was sixty-five years.

Meniscus lesions-The incidence of the lesions is shown in Table I. Thirty-four per cent of the menisci were

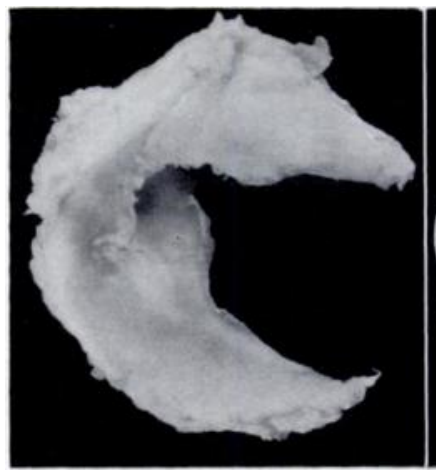

FIG. 4

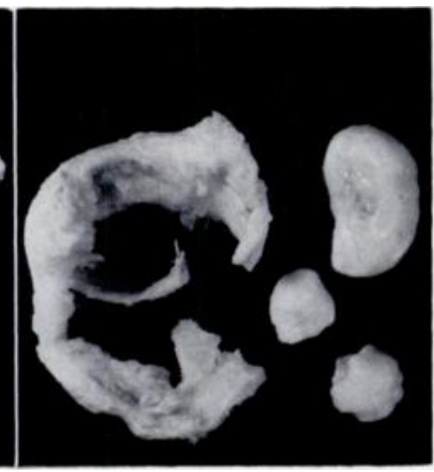

FIG. 5
Figure 4-Parrot beak tear opening into a horizontal cleavage lesion. Figure 5-A very degenerate horizontal cleavage lesion in a meniscus with a parrot beak tear and associated loose bodies.

pathological, with at least one abnormal meniscus in 73 per cent of cadavers. The horizontal cleavage lesion was the most common, in 29 per cent of the 400 menisci, and found in at least one meniscus in 60 per cent of the cadavers

Twenty-six of the thirty parrot beak tears also had a horizontal cleavage lesion (Fig. 4). Twenty of the twenty-seven instances of cystic degeneration were similarly associated. When a horizontal cleavage lesion 


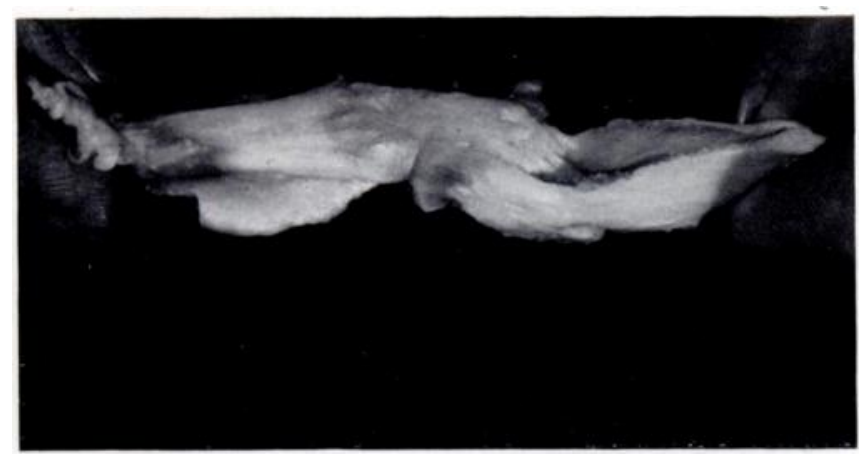

Fig. 6

A view into the concave border of a meniscus showing a horizontal cleavage lesion.

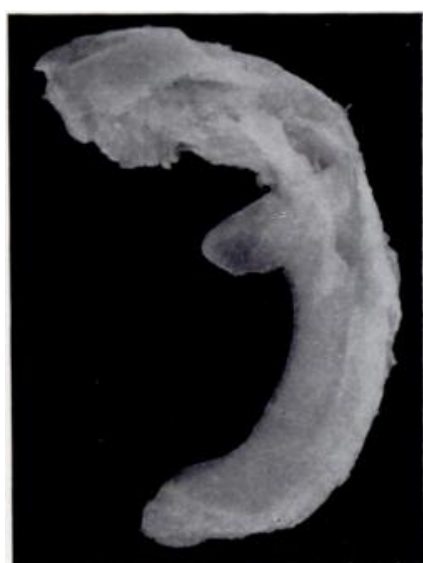

Fig. 7

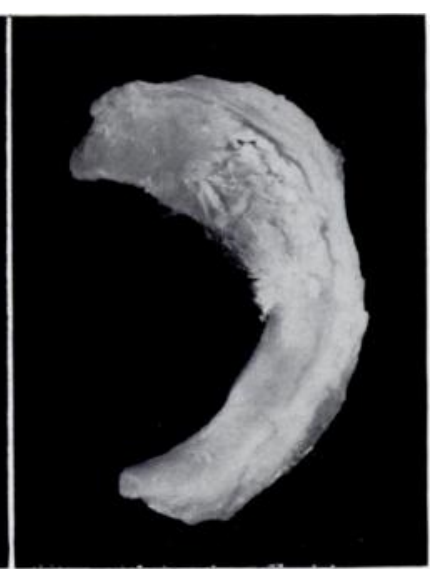

FIG. 8
Figure 7-A meniscus with a horizontal cleavage lesion and a central tag. Figure 8-A meniscus with a frayed and calcified horizontal cleavage lesion.

extended beyond the posterior half of the cartilage, and thus involved the bulk of its structure, it was termed a "massive" lesion. This was seen in 34 per cent of the 117 cleavage lesions and in 25 per cent of the cadavers.

TABLE II

INCIDENCE OF FEMORO-TIBIAL OSTEOARTHRITIS

\begin{tabular}{r|cccc}
\hline $\begin{array}{c}\text { Grade } \\
\text { of } \\
\text { arthritis }\end{array}$ & $\begin{array}{c}\text { Redial } \\
\begin{array}{c}\text { Mediaht knee } \\
\text { compartment }\end{array}\end{array}$ & $\begin{array}{c}\text { Lateral } \\
\text { compartment }\end{array}$ & $\begin{array}{c}\text { Left knee } \\
\text { compartment }\end{array}$ & $\begin{array}{c}\text { Lateral } \\
\text { compartment }\end{array}$ \\
0 & 49 & 38 & 48 & 39 \\
1 & 28 & 35 & 27 & 36 \\
2 & 11 & 20 & 12 & 18 \\
3 & 12 & 7 & 13 & 7 \\
Total & 100 & 100 & 100 & 100 \\
\hline
\end{tabular}

Such menisci may become frayed and destroyed, as is seen in Figure 5. All but eight of the remaining horizontal tears were confined to the posterior half. Such a meniscus is shown in Figure 6, with a horizontal view taken of its concave border. Loose portions of a degenerative meniscus can form polypoidal tags, as is shown in Figure 7 , and these may become displaced towards the joint line. Occasionally, one lamina of the meniscus on one surface

TABLE III

Relationship of Horizontal Cleavage lesions TO OSTEOARTHRITIS

\begin{tabular}{cccc}
\hline $\begin{array}{c}\text { Grade of } \\
\text { osteoarthritis }\end{array}$ & $\begin{array}{c}\text { Number of } \\
\text { joint } \\
\text { compartments }\end{array}$ & $\begin{array}{c}\text { Number with } \\
\text { associated } \\
\text { horizontal } \\
\text { cleavage lesions }\end{array}$ & Percentage \\
\hline 0 & 174 & 32 & $18 \cdot 4$ \\
1 & 126 & 34 & $27 \cdot 0$ \\
2 & 61 & 27 & $44 \cdot 3$ \\
3 & 39 & 24 & $61 \cdot 5$ \\
\hline Total . & 400 & 117 & $29 \cdot 2$ \\
\hline
\end{tabular}

TABLE IV

Distribution of Normal Menisci in Relation TO OSTEOARTHRITIS

\begin{tabular}{ccc}
\hline $\begin{array}{c}\text { Grade of } \\
\text { osteoarthritis }\end{array}$ & $\begin{array}{c}\text { Number of } \\
\text { compartments } \\
\text { with a normal } \\
\text { meniscus }\end{array}$ & $\begin{array}{c}\text { Percentage } \\
\text { of total }\end{array}$ \\
\cline { 1 - 2 } 1 & 142 & $50 \cdot 2$ \\
2 & 92 & $32 \cdot 5$ \\
3 & 34 & $12 \cdot 0$ \\
\hline Total . & 15 & $5 \cdot 3$ \\
\hline
\end{tabular}

of the horizontal cleavage lesion was so frayed as to be substantially worn away. This is shown in Figure 8, where a residual rim of the upper surface can be seen peripherally. Gross calcification is also present.

Other joint pathology-In eight cadavers a loose body was found and in nine a partial or complete tear of a cruciate ligament was present.

Osteoarthritis-Patello-femoral osteoarthritis was seen in 79 per cent of the cadavers and tibio-femoral compartment osteoarthritis in 70 per cent of cadavers (Table II).

\section{TABLE $\mathrm{V}$}

Comparison of Ostfoarthritis and Horizontal Cleavage Lesion in Males and Females

\begin{tabular}{|c|c|c|}
\hline & Male & Female \\
\hline Percentage of cases with a meniscus lesion & 70 & 66 \\
\hline Percentage of cases with a horizontal cleavage lesion & 68 & 53 \\
\hline Percentage of cases with tibio-femoral osteoarthritis & 64 & 77 \\
\hline
\end{tabular}


In only fifteen cadavers were the articular surfaces of both knees macroscopically normal. This does not include the very common observation of fine fibrillation or chondromalacia of the articular cartilage in the nonweight-bearing areas mesial to the menisci. In such cases

TABLE VI

Calcification in Menisci

\begin{tabular}{lccc}
\hline $\begin{array}{c}\text { Pattern of } \\
\text { calcification }\end{array}$ & $\begin{array}{c}\text { Percentage of } \\
\mathbf{1 0 0} \text { cadavers }\end{array}$ & $\begin{array}{c}\text { Percentage of } \\
\mathbf{4 0 0} \text { menisci }\end{array}$ \\
\cline { 2 - 3 } Fern leaf. & 9 & $5 \cdot 5$ \\
Specks & 18 & $10 \cdot 0$ \\
Ossicle & 7 & $2 \cdot 5$ \\
\hline Total & 34 & $18 \cdot 0$ \\
\hline
\end{tabular}

the weight-bearing articular cartilage beneath the meniscus had a normal hyaline appearance macroscopically. The overall incidence for each grade of osteoarthritis in the $\mathbf{4 0 0}$ joint compartments is shown in Table III and is compared with the incidence of horizontal cleavage lesion.

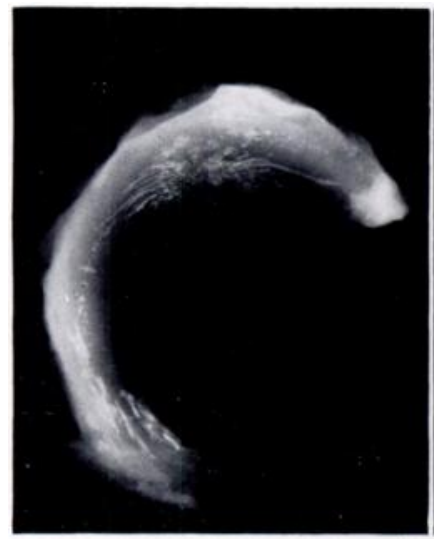

FIG. 9

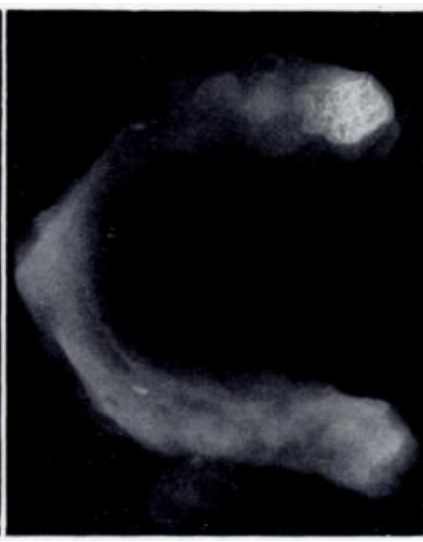

Fig. 10
Figure 9-Radiograph of a meniscus showing fern leaf calcification. Figure 10-Radiograph of a meniscus showing ossicle in posterior horn.

Cleavage lesions were three times as common in grade 3 as in grade 0 compartments. Table IV shows the incidence of normal menisci in each grade of joint compartment and shows that half were present in normal compartments, whereas only 5 per cent were associated with grade 3 osteoarthritis.

Eighty cleavage lesions occurred in a medial compartment and thirty-seven in a lateral compartment. Of the massive horizontal cleavage lesions 42.5 per cent were in joint compartments showing grade 3 osteoarthritis, whereas 32.5 per cent were in grade 0 or grade 1 compartments.

A comparison was made between the incidence of osteoarthritis and of meniscus pathology in the two sexes (Table V). Meniscus degeneration is more common in males than in females in whom articular cartilage degeneration showed a higher incidence.
Calcification-Calcification occurred in 18 per cent of the 400 menisci and was present in at least one meniscus in 34 per cent of the cadavers (Tables I and VI). Of the

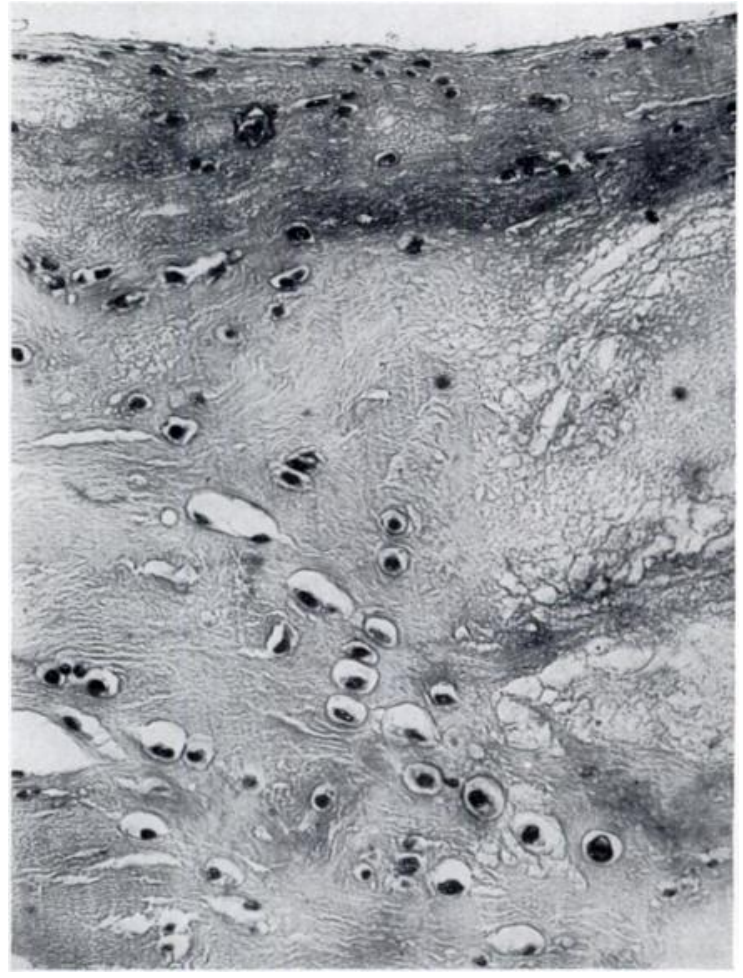

FIG. 11

Mucoid degeneration. Chondrocyte proliferation and degeneration. (Haematoxylin and eosin, $\times 250$.)

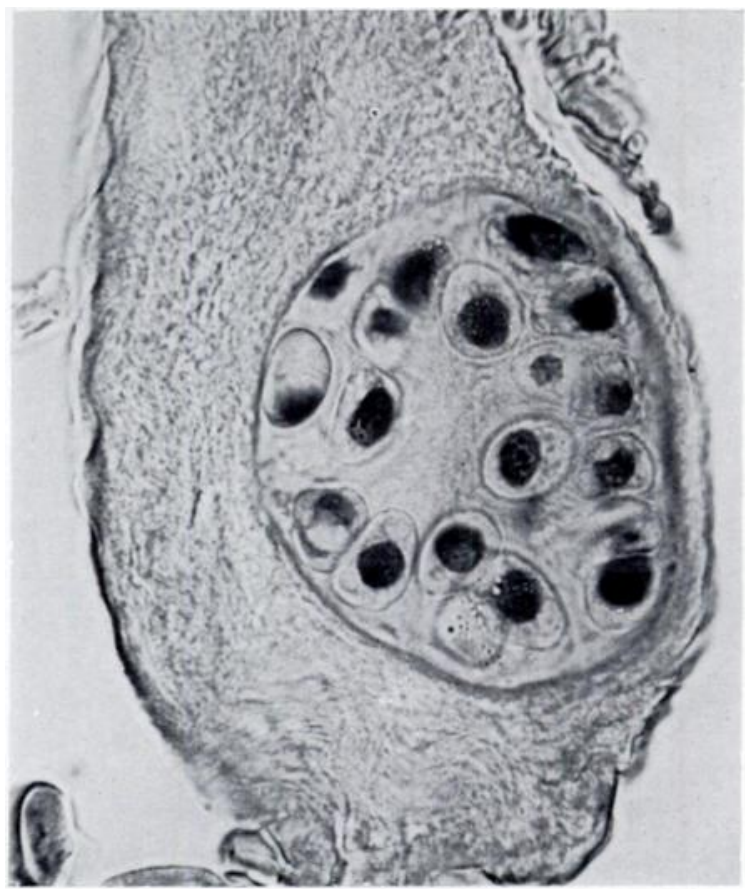

Fig. 12

Clonal aggregation of chondrocytes. (Haematoxylin and eosin, $\times 800$.)

menisci with a horizontal cleavage lesion 26.5 per cent were calcified, compared with only 12 per cent of the macroscopically normal menisci. There were three 


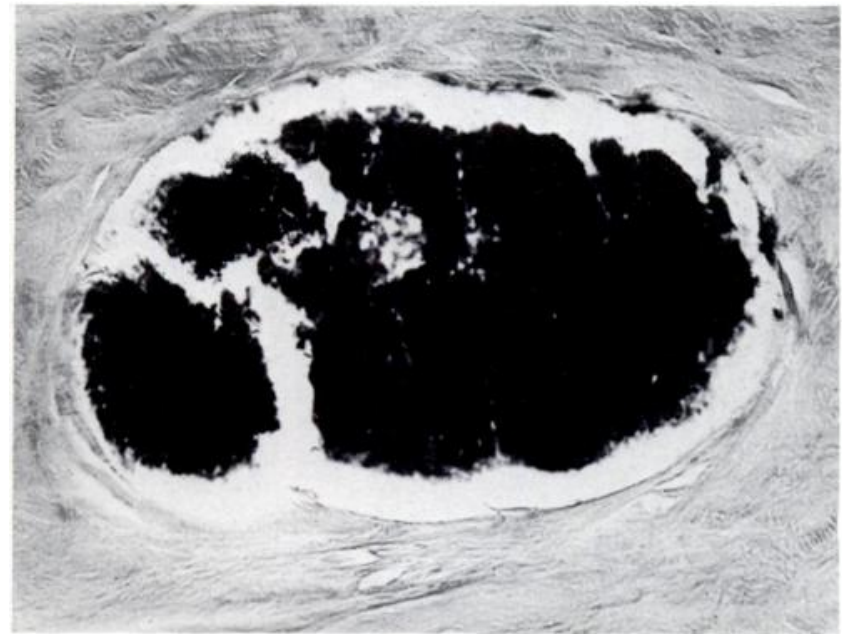

FIG. 13

Calcified cyst. (Von Kossa stain, $\cdot 215$.)

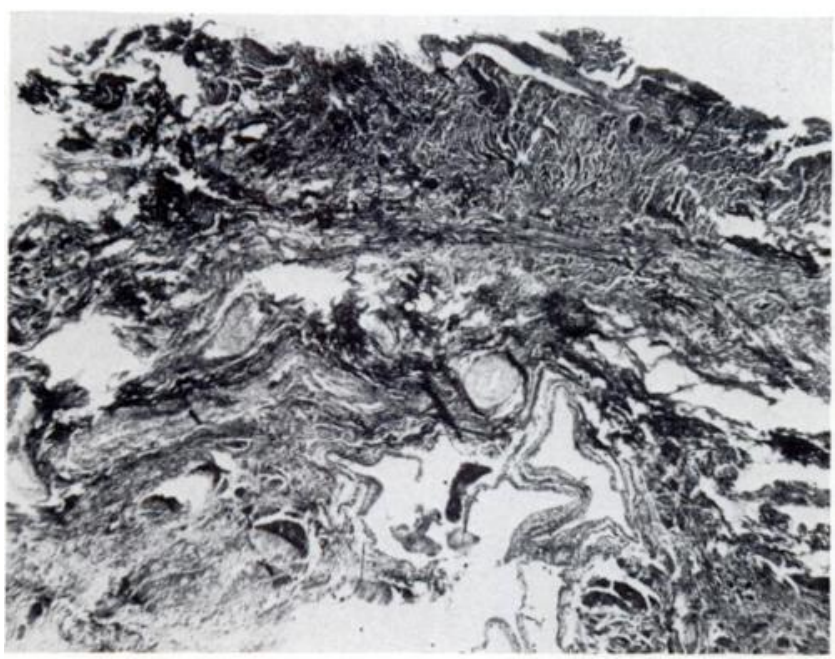

FIG. 14

Plane of cleavage with synovial ingrowth, blood vessels and gross degeneration. (Haematoxylin and eosin, $\therefore 30$.)

calcification patterns, of which the most common was random speckling. More striking was a lace-like pattern, described as fern leaf calcification (Fig. 9). The least common type was circumscribed areas of calcification which sometimes formed ossicles, usually in the posterior horn (Fig. 10).

Microscopy-In the degenerate menisci examined histologically mucoid degeneration of the cartilaginous matrix was seen with chondrocyte proliferation in some areas, whereas death of these cells predominated in other areas of the meniscus (Fig. 11). Clonal aggregation of cells also occurred and was usually seen in more grossly degenerate cartilage (Fig. 12). Increasing eosinophilia of the chondrous matrix was associated with microcyst formation. Calcification occurred in cystic areas (Fig. 13). Collagenisation similar to that of osteoarthritis was seen with fragmentation of collagen bundles. Planes of cleavage developed between fragmenting collagen bundles and into degenerating matrix. Synovial membrane was seen to proliferate into such planes of cleavage and was associated with ingrowth of blood vessels and round-cell proliferation (Fig. 14).

Surface area-The value of the greatest length times breadth product for the medial menisci with a horizontal cleavage lesion was 20.65 as opposed to 16.64 for those without; this is a significant difference $(p<0.001)$. For the lateral menisci the values were $17 \cdot 3$ for the pathological and 15.26 for those macroscopically normal. These differ at a lower level of significance $(p<0.02)$.

Height and weight-There was no correlation between either the height or the weight of the cadavers and the incidence of horizontal cleavage lesion. Moreover, there was no correlation between height or weight and the surface area of the menisci.

\section{DISCUSSION}

Incidence-Although the average age of the cadavers studied was sixty-five years it is noteworthy that the horizontal cleavage lesion was found in 60 per cent. Although there were no orthopaedic histories available it is unlikely that such a percentage of living patients of the same age would have the symptoms of horizontai cleavage lesion, which Smillie (1970) has described. It is possible that the lesions are often symptomless or that the symptoms are either overlooked or ascribed to osteoarthritis.

Pathology - Because the natural history of the two lesions is quite different it is important to distinguish on clinical grounds between degenerate and traumatic tears because it may have relevance in follow-up studies after meniscectomy, particularly if there has been no differentiation between the two diagnoses (Wynn Parry, Nichols and Lewis 1958; Sharrard and Liddell 1962; Jackson 1968; Tapper and Hoover 1969; Johnson, Kettelkamp, Clark and Leaverton 1974).

The acute longitudinal tear is easily distinguished from the horizontal cleavage lesion macroscopically, but it may be difficult microscopically. Pfeil (1966) examined 134 male knees at necropsy and found that 45 per cent had a degenerative meniscus lesion. Upon reviewing 172 meniscectomies he found that 46 per cent had a "partial thickness tear" or a parrot beak tear, whereas 54 per cent had a bucket handle or posterior horn tear. In 1964 Zippel presented 1,360 meniscectomies and concluded that possibly 90 per cent of all meniscus lesions were based upon an intrinsically degenerative process and all the menisci that were examined microscopically showed degenerative changes, including those which appeared normal to the naked eye. However, Zippel's breakdown of the cases was traditional, 70 per cent of the tears being longitudinal and only 1.4 per cent showing cleavage attrition and cavity formation. Tarjany and Radochay (1966) believed that a long-standing traumatic lesion which is not removed may predispose to degenerative changes in the meniscus. This may well be so, but 
Lehtonen, Viljanto and Kärkkäinen (1967), studying mucopolysaccharide content, found that traumatic tearing of the menisci did not cause the changes in acid mucopolysaccharide content characteristic of fibrocartilage degeneration. Particularly in view of the microscopic findings, it is probable that an injury may cause a horizontal cleavage tear in a meniscus which already had fibrocartilaginous degeneration.

Microscopy-Degeneration may originate in the chondrocyte. Taylor and Little (1965) expressed such a view after studies of intervertebral disc degeneration. In the menisci in this series vascular tissue was often seen with synovial membrane in the planes of cleavage, a fact which may have some bearing upon the origin of such clinical symptoms as night pain and tenderness. Microscopical degeneration was an almost invariable finding in patients over the age of forty and was as common in lateral as in medial menisci. Thus in the older subjects with uniform degeneration of ground substance and collagen other factors are likely to cause the severe tearing of the horizontal cleavage lesion.

Relationship to osteoarthritis-_Lidge (1970) suggested that meniscus degeneration is a complication of osteoarthritis but Frankel, Burstein and Brooks (1971) suggested that a remote meniscus injury may cause osteoarthritis. In this series the relationship of horizontal cleavage lesion to the presence and severity of osteoarthritis was studied and its incidence was found to increase with the severity of osteoarthritis. Half the joint compartments containing a normal meniscus also showed normal articular cartilage, whereas only 17.7 per cent of the normal menisci were found in joints showing grade 2 or grade 3 osteoarthritis. At first sight this appears to be a direct relationship, but further study casts some doubt on it. With the cleavage lesion being so common it is remarkable that fifteen of the thirty-nine severely degenerate (grade 3 ) joint compartments contained a meniscus which was normal macroscopically. Conversely, 18.4 per cent of the normal joint compartments contained a meniscus with a horizontal cleavage lesion and this included one-third of the massive cleavage lesions.

Horizontal cleavage lesions were twice as common in the medial as in the lateral compartment, whereas in this series osteoarthritis was more common in the lateral compartment, in the ratio of six to five. Wiley (1968) also found lateral compartment osteoarthritis to be commoner than medial. The pattern of the two lesions is distinct, and this is borne out further by finding that a horizontal cleavage lesion was found more often in males than in females, whereas the reverse was the case with osteoarthritis. In conclusion, therefore, it seems more likely that the two conditions may often co-exist rather than be causally related.

The finding of chondromalacia in the mesial nonweight-bearing articular cartilage corresponds to identical observations in the elbow joint by Goodfellow and Bullough (1967) who mentioned that in a few cases they had seen the same change in the knee but regarded it as a different condition from the gross osteoarthritic changes of old age. They believed that there was an aetiological association between the two conditions, possibly because of a break in the integrity of the cartilage micro-architecture. Surface area-The study of surface area suggests that the horizontal cleavage lesion is more liable to occur in both large and medial menisci, although microscopically degenerative changes are almost invariable in all the menisci of the elderly. The firmer attachments of the medial meniscus may predispose to greater shearing forces within the meniscus, producing gross laminar tearing. Shute (1967) has shown from radiological analysis of knee joint movements that the lateral meniscus tends to move with the femur whereas the medial meniscus does not. If the final rotation mechanism of the medial femoral condyle in full extension is a factor causing horizontal tearing, the larger meniscus could be more vulnerable.

Size of patient-Lack of correlation between cadaver weight and the incidence of horizontal cleavage lesion indicates that obesity is not important in its aetiology. This may be another difference from the clinical pattern of osteoarthritis. As there was no correlation between meniscus surface area and the size of the patient, it seems that it is the surface area of the cartilage exposed to shearing forces which is critical, rather than the size of the patient.

Calcification-Calcification was twice as common in those menisci with a cleavage lesion as in those without, and may be secondary to degenerative changes. Schubert and Pras (1968) have shown that a loss of chondroitin sulphate is characteristic of intervertebral disc degeneration and that this predisposes to calcium phosphate precipitation. The incidence of 34 per cent of the cases showing calcification in at least one meniscus is very similar to the findings of McCarty, Hogan, Gatter and Grossman (1966). They also distinguished between punctate and linear patterns and suggested that this latter type may underlie the syndrome of chondrocalcinosis.

We would like to thank the University Department of Pathology for access to specimens, and particularly Dr J. Habeshaw, who reviewed the microscopy. We are also most grateful to Professor E. Samuel and Dr G. B. Young, who provided facilities for radiography of the menisci, and Professor J. I. P. James and Professor I. S. Smillie, who originally stimulated this study. Finally our thanks are due to Mr John Chalmers, Dr Barry King and Professor David Simpson for their most helpful suggestions and criticisms.

\section{REFERENCES}

Chand, K. (1972) Horizontal (cleavage) tears of the knee-joint menisci in the elderly. Journal of the American Geriatrics Society, 20, $430-433$. Eichenholtz, S. N., Jacobs, B., and Patterson, R. L., Jun. (1968) Meniscus injuries of the knee in the elderly. Journal of the American Geriatrics Society, 16, 281-289. 
Frankel, V. H., Burstein, A. H., and Brooks, D. B. (1971) Biomechanics of internal derangement of the knee. Pathomechanics as determined by analysis of the instant centers of motion. Journal of Bone and Joint Surgery, 53-A, 945-962.

Goodfellow, J. W., and Bullough, P. G. (1967) Patterns of ageing in human joints. In Lubrication and wear in living and artificial human joints. Conference held in London on Friday, April 7, 1967. Proceedings of the Institution of Mechanical Engineers (London), 181, iiiJ, 129-132.

Jackson, J. P. (1968) Degenerative changes in the knee after meniscectomy. British Medical Journal, 2, 525-527.

Johnson, R. J., Kettelkamp, D. B., Clark, W., and Leaverton, P. (1974) Factors affecting late results after meniscectomy. Journal of Bone and Joint Surgery, 56-A, 719-729.

Lehtonen, A., Viljanto, J., and Kärkkäinen, J. (1967) The mucopolysaccharides of herniated human intervertebral discs and semilunar cartilages. Acta chirurgica Scandinavica, 133, 303-306.

Lidge, R. T. (1970) Medial meniscectomy in the osteoarthritic knee. Clinical Orthopaedics and Related Research, 68, 63-71.

McCarty, D. J., Jun., Hogan, J. M., Gatter, R. A., and Grossman, M. (1966) Studies on pathological calcification in human cartilage. I. Prevalence and types of crystal deposits in the menisci of two hundred and fifteen cadavers. Journal of Bone and Joint Surgery, 48-A, 309-325.

Pfeil, E. (1966) Meniskusläsion und Alter. Zeitschrift für Orthopädie und ihre Grenzgebiete, 102, 308-309.

Schubert, M., and Pras, M. (1968) Ground substance proteinpolysaccharides and the precipitation of calcium phosphate. Clinical Orthopaedics and Related Research, 60, 235-255.

Scott, W. P., Willemin, A., and Betsch, C. (1967) Fundamentals of soft tissue radiography (mammography). Radiologic Clinics of North America, 5, 169-180.

Sharrard, W. J. W., and Liddell, F. D. K. (1962) Injuries to the semilunar cartilages of the knee in miners. British Journal of Industrial Medicine, 19, 195-202

Shute, C. C. D. (1967) Complex movements at the knee joint. In Lubrication and wear in living and artificial human joints. Conference held in London on Friday, April 7, 1967. Proceedings of the Institution of Mechanical Engineers (London), 181, iiiJ, 121.

Sideman, S., and Siegel, I. M. (1962) Meniscal derangement in the osteoarthritic knee joint. Journal of the American Medical Association, $182,626-628$

Simmonds, F. A. (1964) The immobile meniscus. A common syndrome in middle age. Postgraduate Medical Journal, 40, 527-528.

Smillie, I. S. (1962) Injuries of the Knee Joint. Third edition, p.60. Edinburgh and London: E. and S. Livingstone Ltd.

Smillie, I. S. (1967) The current pattern of internal derangements of the knee joint, relative to the menisci. Clinical Orthopaedics and Related Research, 51, 117-122.

Smillie, I. S. (1970) Injuries of the Knee Joint. Fourth edition, p.79. Edinburgh and London: E. and S. Livingstone Ltd.

Smith, F. B., and Blair, H. C. (1954) Tibial collateral ligament strain due to occult derangements of the medial meniscus. Journal of Bone and Joint Surgery, 36-A, 88-92.

Tapper, E. M., and Hoover, N. W. (1969) Late results after meniscectomy. Journal of Bone and Joint Surgery, 51-A, 517-526.

Tarjányi, J., and Radochay, L. (1966) Meniskusverletzungen oder Degeneration des Meniskus. Beiträge zur orthopädische Trauma, 13, $660-661$.

Taylor, T. K. F., and Little, K. (1965) Intercellular matrix of the intervertebral disk in ageing and in prolapse. Nature (London), $208,384-386$

Wiley, A. M. (1968) Pathological and clinical aspects of degenerative disease of the knee. Canadian Journal of Surgery, 11, 14-22.

Wynn Parry, C. B., Nichols, P. J. R., and Lewis, N. R. (1958) Meniscectomy: a review of 1,723 cases. Annals of Physical Medicine, 4, $201-215$.

Zippel, H. (1964) Meniscusschäden und Meniscusverletzungen. Eine Untersuchung an 1360 Meniscusoperationen. Archiv fïr Orthopädische und Unfall-Chirurgie, 56, 236-247. 